\title{
No pain, no gain?
}

\section{Tom Jacobs}

According to Pain Therapeutics $2005^{1}, 1.5$ billion people suffer from moderate to severe chronic pain, representing a worldwide drug market of $\$ 23$ billion last year. Patients take NSAIDs (nonsteroidal anti-inflammatory drugs), anticonvulsants, cyclooxygenase 2 (COX-2) inhibitors, opioids and even antidepressants, among others. Because many of these analgesics are only moderately effective against chronic pain and often cause debilitating side effects (e.g., nausea, dizziness or respiratory depression), interest is great in finding new therapeutic approaches, such as Élan Pharmaceuticals' (Dublin, Ireland; NYSE:ELN) peptide Prialt (ziconotide) and Pfizer's (New York, NY, USA; NYSE:PFE) small molecule Lyrica (pregabalin), a more powerful version of a prior Pfizer drug (Nat. Biotechnol. $23,399,2005)$

Although Prialt and Lyrica might represent a new generation of painkillers, in the meantime, R\&D continues apace on more traditional opioid pain relievers, which in 2003 had a market of $\$ 5.6$ billion in the US alone. The most wellknown opioid is privately held Purdue Pharma's (Stamford, CT, USA) OxyContin (oxycodone $\mathrm{HCl}$ ), controversial for its recreational abuse. At the moment, two companies are competing with Purdue for a slice of OxyContin's market: Ligand Pharmaceuticals (San Diego, CA, USA; Nasdaq: LGNDE) has a product with the advantage of only once-a-day use; S. San Francisco, California-based private venture Pain Therapeutics sports two potential competing drugs (one different from OxyContin, the other a variation of it) that promise less addiction potential. Yet each company provides very different risk and reward profiles for investors.

\section{Unconvinced by Avinza}

Ligand Pharmaceuticals copromotes its oncea-day opioid Avinza (morphine sulfate) with

Tom Jacobs is cofounder of Complete Growth Investor (http://www.completegrowth. $\mathrm{com} /$ ). Tom owns no shares of companies in this column. He welcomes your comments at tom@completegrowth.com.
Akzo Nobel's (Arnhem, Netherlands; Nasdaq: AKZOY) Organon unit for moderate-to-severe chronic pain. The deal, when announced, catalyzed Ligand's stock price, boosting it from the low single digits in early 2004 into the $\$ 20$ range a year later. Two main factors have since humbled the price, now around $\$ 6$.

First, Avinza, despite its greater convenience and therefore easier administration in a highly regulated arena, had a mere $\$ 74.1$ million in sales in the first three-quarters of 2004 and is Ligand's top-selling drug. Despite repeated management promises of imminent profitability, Ligand has never moved into the black on an annual basis, and with several years since its March 2002 approval, Avinza now appears unlikely to fuel that shift. Though researchers presented positive phase 2 trial data for Ligand's Targretin (bexarotene) for non-smallcell lung cancer at May's American Society of Clinical Oncology meeting, Targretin is still years from potential approval or sales for this indication.

Second, the company in March announced that it would delay filing annual and quarterly reports owing to review of its accounting practices for revenue recognition involving sales of Avinza and also sales of royalty rights. Oh dear. This development has hammered the stock price, but it has also piqued contrarian investors to ask whether this is an opportunity to invest in a company that while now ugly, is cheap enough?

\section{Ugly but cheap?}

I'm wary. With uncertainty over the company's sales, accounts receivable and inventory valuation, it's hard to value the company with any confidence. And I have little faith in management, which at best has earned the reputation of the boy who cried wolf. Better to wait to see the financial restatements.

There's also an important lesson here for the whole opioid pain market. Avinza's mediocre sales ramp underscores how hard it is to crack this highly regulated universe. The market may be substantial, but when a drug offering Avinza's advantages hasn't yet dented it, investors should be extra cautious.

\section{An attractive speculation}

The difficulty in penetrating the market may be one reason why opioid treatment speculation hasn't yet seen emotional price gains. Formed in 1998, Pain Therapeutics' pipeline consists of three drugs, all in phase 3 trials in the United States and showing positive data: OxyTrex (oxycodone plus ultra-low dose naltrexone $\mathrm{HCl}$ ) is a new opioid painkiller intended for severe chronic pain; Remoxy (oxycodone in gel cap prolonged release form) is an antiabuse form of the opioid oxycodone for pain; and PTI-901 (naltrexone $\mathrm{HCl}$ ) is for irritable bowel syndrome (IBS). This March, the company released trial data for OxyTrex showing "minimal physical dependence, better overall safety, less drug use, and similar pain relief to oxycodone" with fewer undesirable side effects. What more could anyone ask for?

Plus the company is in a healthy financial position. At the end of March 2005, Pain Therapeutics had no debt and over $\$ 90$ million in cash. Burning a third of that per year, it likely can fund its late-stage drug development through the US Food and Drug Administration decision making. What's more, should approval come, the company's $100 \%$ ownership of the drugs means excellent profits or a favorable marketing deal to boost future revenues.

Opioids are likely to remain big business in alleviating pain suffering for some time, but new entrants face formidable obstacles. It's essential to examine the management, financials and pipeline of the opioid drug maker. I'm jaded on Ligand, having seen it snatch defeats from the jaws of victory too often, but remain open to it as a contrarian investment after viewing its restated financials. Pain Therapeutics is an attractive speculation. Kept to a small part of an aggressive investor's portfolio, shares offer an attractive potential reward for the risk-for more profit than pain.

1. Pain Therapeutics 2005: Market Dynamics and Outlook (Arrowhead Publishers, New York, May 2005). 